\title{
The clinical and prognostic impact of aldehyde dehydrogenase 1 in non-small cell lung cancer: a meta-analysis
}

\author{
Jinru Xue ${ }^{1}$, Yan Zhao' ${ }^{2}$ Qingxu Zou', Feihai Liang ${ }^{3}$, Fengwu Lin ${ }^{1}$ \\ ${ }^{1}$ Department of Thoracic Surgery, China-Japan Union Hospital of Jilin University, Changchun 130033, China; ${ }^{2}$ Medical Examination Center, \\ the Second Hospital of Jilin University, Changchun 130041, China; ${ }^{3}$ Cardiovascular Thoracic Surgery, the Second Affiliated Hospital of Guangxi \\ Medical University, Nanning 530007, China \\ Contributions: (I) Conception and design: J Xue, F Lin; (II) Administrative support: F Lin; (III) Provision of study materials or patients: J Xue, F Lin; \\ (IV) Collection and assembly of data: J Xue, Y Zhao; (V) Data analysis and interpretation: Q Zou, F Lin; (VI) Manuscript writing: All authors; (VII) \\ Final approval of manuscript: All authors. \\ Correspondence to: Fengwu Lin. Department of Thoracic Surgery, China-Japan Union Hospital of Jilin University, 126 Xiantai Street, Changchun \\ 130033, China. Email: fengwulin@hotmail.com.
}

Background: Aldehyde dehydrogenase 1 (ALDH1) has been identified as a cancer stem cell marker. However, the clinical role of ALDH1 in non-small cell lung cancer (NSCLC) remains conflicting. This study was conducted to investigate the correlation of ALDH1 with NSCLC patients' clinicopathological characteristics and prognosis.

Methods: The electronic databases were searched for the available literature. The pooled odds ratios (ORs) with 95\% confidence intervals (CIs) or hazard ratios (HRs: multivariate Cox analysis) with 95\% CIs were used to evaluate the impact of ALDH1 on NSCLC.

Results: Final 13 eligible studies with 2,407 patients published between 2009 and 2019 were identified. ALDH1 expression was not correlated with age, gender, smoking behavior, clinical stage, histological grade, lymph node metastasis, and distal metastasis, but the results demonstrated a positive association of ALDH1 expression with recurrence (yes vs. no: $\mathrm{OR}=2.82,95 \% \mathrm{CI}, 1.17-6.80, \mathrm{P}=0.021$ ) and a negative association of ALDH1 expression with vascular invasion (positive $v$. negative: $\mathrm{OR}=0.63,95 \% \mathrm{CI}, 0.41-0.98, \mathrm{P}=0.04$ ). ALDH1 expression was significantly lower in adenocarcinoma (AD) than in squamous cell carcinoma (SCC) (OR $=0.39,95 \%$ CI, 0.30-0.51, $\mathrm{P}<0.001)$. Multivariate Cox analysis showed that ALDH1 expression was not associated with overall survival (OS) and disease-free survival (DFS), but was correlated with improved disease-specific survival (DSS) (HR =0.47, 95\% CI, 0.22-0.98, $\mathrm{P}=0.043$ ).

Conclusions: ALDH1 expression may be an independent favorable prognostic marker for DSS in NSCLC.

Keywords: Non-small cell lung cancer (NSCLC); aldehyde dehydrogenase 1 (ALDH1); cancer stem cell; adenocarcinoma; prognosis

Submitted Dec 05, 2019. Accepted for publication Jan 16, 2020.

doi: $10.21037 /$ tcr.2020.02.09

View this article at: http://dx.doi.org/10.21037/tcr.2020.02.09

\section{Introduction}

Lung cancer is recognized as the most common and lethal malignancy in the world (1). The GLOBOCAN estimates report that approximately 2,093,876 new cases with lung cancer are diagnosed, with 1,761,007 estimated deaths in 2018 worldwide (1). Non-small cell lung cancer (NSCLC) is the most common type of lung cancer, accounting for about $85 \%$ of all lung cancer patients (2). The patients with NSCLC have a poor prognosis, with a 5 -year survival rate of $<17 \%$ (3). Adenocarcinoma (AD) and squamous cell carcinoma (SCC) are two main histological subtypes of NSCLC (4). 
Cancer stem cells (CSCs), a small subset within tumor cells, show the potential capacities of self-renewal, aberrant differentiation, and tumor formation. CSCs are reported to be responsible for tumor progression, relapse, prognosis, and therapeutic resistance (5-8). Aldehyde dehydrogenase 1 (ALDH1), a cytosolic enzyme, involves in oxidation and detoxification functions (9). ALDH1 has been shown as a CSC mark. ALDH1 is reported to be associated with retinoid metabolism, colony formation, epithelialto-mesenchymal-transition (EMT), and cell migration and invasiveness (10-13). Moreover, ALDH1 is related to resistance to chemotherapy and radiation and the prognosis of cancer $(14,15)$. The expression of ALDH1 could be detected and is correlated with worse prognosis in numerous human cancers such as ovarian cancer, esophageal cancer, and bladder cancer $(13,16,17)$. Recent studies have demonstrated that ALDH1 is frequently expressed in patients with NSCLC (18-20).

However, the results of clinical studies about ALDH1 remain controversial in NSCLC. For example, Park 2016 et al. reported that ALDH1 was not associated with overall survival (OS) using multivariate Cox analysis in NSCLC (20). While Zhou 2016 et al. reported that ALDH1 expression was correlated with a poor OS using multivariate Cox analysis in NSCLC (19). To determine the clinical and prognostic effects of ALDH1 in NSCLC, the present metaanalysis via pooling eligible studies was conducted. This analysis may clarify the role of ALDH1 as a molecular target in predicting NSLCL patients' outcomes.

\section{Methods}

\section{Literature search}

The current meta-analysis was performed in accordance with the Preferred Reporting Items for Systematic Review and Meta-analysis (PRISMA) statement (21). The PubMed, EMBASE, Web of Science, and Cochrane Library databases were searched to achieve available publications before July 23, 2019. We applied the following keywords and search terms: "(aldehyde dehydrogenase 1 OR ALDH1)", "pulmonary OR lung," "cancer OR tumor OR carcinoma OR neoplasm." Additionally, the references of the included publications were also carefully checked to obtain additional studies.

\section{Study selection}

The eligible studies met the following selection criteria were included: (I) the patients with NSCLC were diagnosed; (II) ALDH1 using the anti-ALDH1 antibody in human tissue samples was examined by immunohistochemical (IHC) or immunofluorescence (IF) methods; (III) ALDH1 expression was considered as positive or negative based on the original publications; (IV) studies proved available data to estimate the correlation of ALDH1 expression with the clinicopathological characteristics; (V) according to multivariate Cox analysis, studies provided available hazard ratio (HR) with $95 \%$ confidence interval (CI) to evaluate clinical outcomes of ALDH1 expression in NSCLC patients; (VI) in the case of insufficient data, the corresponding author was contacted through email address. When authors published more than one paper using overlapping tissue specimens, only the recent publication or the publication with more detailed information was selected. The main exclusion criteria were: (I) articles reported data on other antibodies such as anti-ALDH1A1 antibody; (II) articles reported data on univariate Cox survival analysis; (III) studies did not apply IHC or IF to detect ALDH1 expression; (IV) only studies regarding animals or cell lines; (V) reviews, editorials, conference abstracts, case reports, letters, and studies with insufficient information.

\section{Data extraction}

Data from full-text articles were reviewed and extracted as follows: first author's surname, publication year, country, ethnicity, testing method, median/mean age, disease stage, histology, relevant antibody information, the cut-off values of ALDH1, sample size, expression frequency of ALDH1, clinical features such as age, gender, smoking behavior, clinical stage, histological grade, histologic subtype, vascular invasion, lymph node metastasis, distal metastasis, and recurrence, and the prognostic data of multivariate Cox analysis such as OS, disease-specific survival (DSS), diseasefree survival (DFS), and recurrence-free survival (RFS). Any disagreements on data were resolved by all authors' discussion.

\section{Statistical analysis}

Data were analyzed by using Stata software, version 12.0 (Stata Corp., College Station, TX, USA). The combined odds ratios (ORs) and $95 \%$ CIs were used to assess the correlation between ALDH1 expression and the clinicopathological features, including age, gender, smoking behavior, clinical stage, histological grade, histologic 


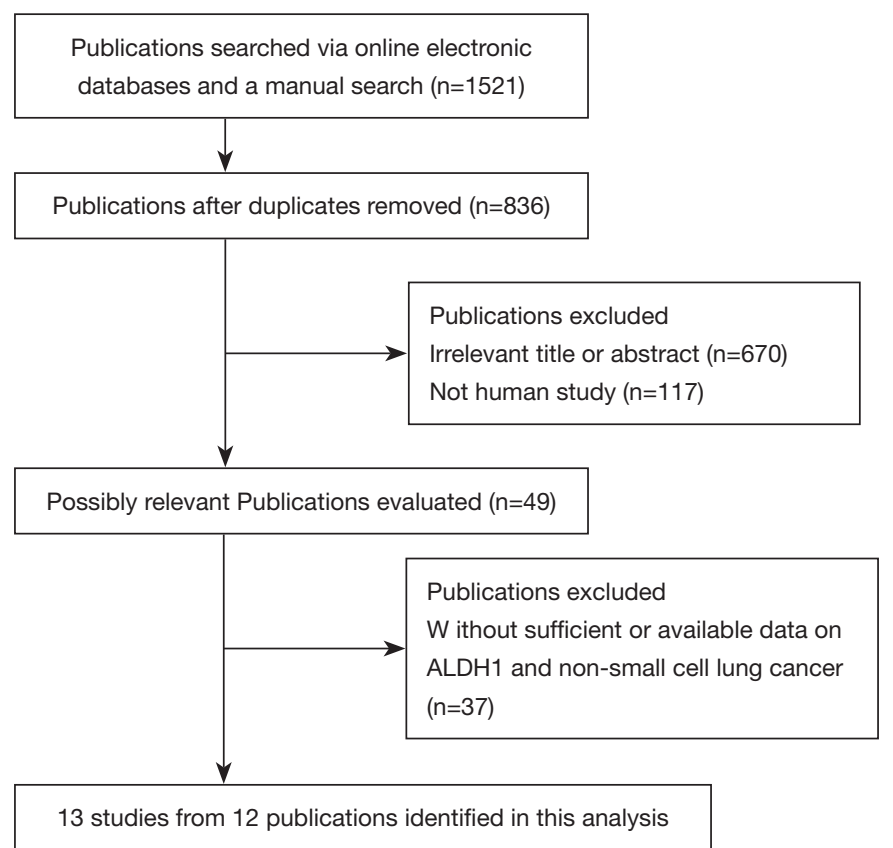

Figure 1 Flow diagram of the meta-analysis process. ALDH1, aldehyde dehydrogenase 1.

subtype, vascular invasion, lymph node metastasis, distal metastasis, and recurrence. The combined HRs and their 95\% CIs were employed to assess the association between ALDH1 expression and the prognosis using multivariate Cox analysis. The random-effects model was applied in the present meta-analysis. The statistical heterogeneity between studies was estimated by using Cochran's Q statistic (22), a $\mathrm{Q}$ test of $\mathrm{P}$ value of less than 0.1 stood for substantial heterogeneity. When substantial heterogeneity was measured, sensitivity analyses were carried out by omitting an individual study to confirm the change of the re-calculated results and heterogeneity. The Egger's test was employed to measure the possible publication bias (23).

\section{Results}

\section{Study characteristic}

The flowchart summarizing the process of the study selection is shown in Figure 1. After carefully reviewing article titles, abstracts, and full text, final 13 eligible studies from 12 publications (18-20,24-32) met the inclusion criteria were included in this meta-analysis, including 2,407 patients with NSCLC. The included studies were published from 2009 to 2019 and were conducted in the USA, Austria, Iran, China, Korea, and
Japan. Among these studies, 10 studies, including 1,925 NSCLC patients, evaluated the relationship of ALDH1 expression with the clinicopathological characteristics (18-20,24,25,27-29,31,32). Seven studies from six publications provided available HR with $95 \%$ CI of multivariate Cox analysis to evaluate the prognostic effect of ALDH1 expression (18-20,26,29,30), including 1,266 NSCLC patients. Table 1 and Table S1 list the main characteristics of the selected publications.

\section{Association of ALDH1 expression with clinicopathological features}

As shown in Table 2, the relationships of ALDH1 expression with clinicopathological features of patients with NSCLC were summarized. ALDH1 expression was not correlated with age (two studies with 270 cases, $\geq 60$ vs. $<60$ years: $\mathrm{OR}=0.96,95 \% \mathrm{CI}, 0.59-1.57, \mathrm{P}=0.883$ ), gender (five studies with 731 cases, male $v$ s. female: $\mathrm{OR}=1.09,95 \% \mathrm{CI}$, $0.79-1.50, \mathrm{P}=0.617$ ), and smoking behavior (three studies with 385 cases, smoking vs. nonsmoking: $\mathrm{OR}=1.27,95 \%$ CI, 0.81-1.98, $\mathrm{P}=0.292$ ) (Figure 2).

No relationship was found between ALDH1 expression and clinical stage (five studies with 1,163 cases, stage 3-4 vs. $1-2$ : $\mathrm{OR}=1.55,95 \% \mathrm{CI}, 0.47-5.17, \mathrm{P}=0.473)$ and histological grade (five studies with 712 cases, grade 3 vs. 
Table 1 Main characteristics of the eligible publications

\begin{tabular}{|c|c|c|c|c|c|c|c|c|c|c|c|c|}
\hline $\begin{array}{l}\text { First } \\
\text { author }\end{array}$ & Country & Age & Method & Stage & Histology & Antibody & Sources of antibody & Staining & Cut-off values & $\begin{array}{c}\text { Cancer } N \\
(E+\%)\end{array}$ & $\begin{array}{l}\text { Clinical } \\
\text { features }\end{array}$ & $\begin{array}{c}\text { MA- } \\
\text { survival } \\
\text { with HR }\end{array}$ \\
\hline $\begin{array}{l}\text { Jiang } \\
2009\end{array}$ & USA & NA & $\mathrm{IHC}$ & $1-4$ & NSCLC & $\begin{array}{l}\text { anti-ALDH1 } \\
\text { antibody }\end{array}$ & $\begin{array}{c}\text { Santa Cruz } \\
\text { Biotechnology }\end{array}$ & Cytoplasm & $>10 \%$ & $208(22.1 \%)$ & Yes & NA \\
\hline $\begin{array}{l}\text { Shien } \\
2012\end{array}$ & Japan & NA & $\mathrm{IHC}$ & 3 & NSCLC & $\begin{array}{l}\text { anti-ALDH1 } \\
\text { antibody }\end{array}$ & $\begin{array}{c}\text { Abcam, Cambridge, } \\
\text { UK }\end{array}$ & NA & $>10 \%$ & $30(60 \%)$ & Yes & NA \\
\hline $\begin{array}{l}\text { Dimou } \\
2012\end{array}$ & USA & 66 & IF & $1-4$ & NSCLC & $\begin{array}{l}\text { anti-ALDH1 } \\
\text { antibody }\end{array}$ & Dako, Carpinteria, CA & Cytoplasm & $\begin{array}{c}>\text { AQUA score } \\
\text { of } 1,200\end{array}$ & $134(86.6 \%)$ & No & DSS \\
\hline $\begin{array}{l}\text { Dimou } \\
2012\end{array}$ & USA & 65 & IF & $1-4$ & NSCLC & $\begin{array}{l}\text { anti-ALDH1 } \\
\text { antibody }\end{array}$ & Dako, Carpinteria, CA & Cytoplasm & $\begin{array}{c}\text { >AQUA score } \\
\text { of } 1,200\end{array}$ & $296(84.5 \%)$ & No & DSS \\
\hline $\begin{array}{l}\text { Okudela } \\
2012\end{array}$ & Japan & 68 & $\mathrm{IHC}$ & 1 & $A D$ & $\begin{array}{l}\text { anti-ALDH1 } \\
\text { antibody }\end{array}$ & $\begin{array}{c}\text { Abcam, Cambridge, } \\
\text { UK }\end{array}$ & $\begin{array}{l}\text { Cytoplasm/ } \\
\text { membrane }\end{array}$ & $\geq 85 \%$ & $177(20.3 \%)$ & Yes & DFS \\
\hline $\begin{array}{l}\text { Kirita } \\
2013\end{array}$ & Japan & 67 & $\mathrm{IHC}$ & NA & $A D$ & $\begin{array}{l}\text { anti-ALDH1 } \\
\text { antibody }\end{array}$ & $\begin{array}{c}\text { clone 44ALDH; BD } \\
\text { Bioscience, San Jose, } \\
\text { CA, USA }\end{array}$ & Cytoplasm/nuclei & Median & $107(33.6 \%)$ & Yes & NA \\
\hline $\begin{array}{l}\text { Zenke } \\
2013\end{array}$ & Japan & 64 & $\mathrm{IHC}$ & $1-4$ & NSCLC & $\begin{array}{l}\text { anti-ALDH1 } \\
\text { antibody }\end{array}$ & $\begin{array}{c}\text { clone 44/ALDH; BD } \\
\text { Bioscience }\end{array}$ & NA & Median & $52(50 \%)$ & No & DFS \\
\hline $\begin{array}{l}\text { Sterlacci } \\
2014\end{array}$ & Austria & NA & $\mathrm{IHC}$ & $1-4$ & NSCLC & $\begin{array}{l}\text { anti-ALDH1 } \\
\text { antibody }\end{array}$ & $\begin{array}{l}\text { Clone ab51028, } \\
\text { Abcam }\end{array}$ & Cytoplasm & Median & $336(31.8 \%)$ & Yes & NA \\
\hline $\begin{array}{l}\text { Koriyama } \\
2015\end{array}$ & Japan & 64 & $\mathrm{IHC}$ & $1-4$ & $A D$ & $\begin{array}{l}\text { anti-ALDH1 } \\
\text { antibody }\end{array}$ & $\begin{array}{c}\text { Clone 44/ALDH, BD } \\
\text { Biosciences }\end{array}$ & NA & $>50 \%$ & $87(32.2 \%)$ & Yes & NA \\
\hline $\begin{array}{l}\text { Roudi } \\
2015\end{array}$ & Iran & NA & $\mathrm{IHC}$ & NA & NSCLC & $\begin{array}{l}\text { anti-ALDH1 } \\
\text { antibody }\end{array}$ & $\begin{array}{l}\text { ab52492, Abcam, } \\
\text { Cambridge, UK }\end{array}$ & Cytoplasm & H-score of 27 & 105 (22.9\%) & Yes & NA \\
\hline $\begin{array}{l}\text { Park } \\
2016\end{array}$ & Korea & 64 & $\mathrm{IHC}$ & $1-4$ & NSCLC & $\begin{array}{l}\text { anti-ALDH1 } \\
\text { antibody }\end{array}$ & $\begin{array}{c}\text { BD Biosciences, San } \\
\text { Diego, CA }\end{array}$ & Cytoplasm & $\begin{array}{c}\text { >total score of } \\
100\end{array}$ & $368(57.3 \%)$ & Yes & OS, DFS \\
\hline $\begin{array}{l}\text { Zhou } \\
2016\end{array}$ & China & 58 & $\mathrm{IHC}$ & $1-3$ & NSCLC & $\begin{array}{l}\text { anti-ALDH1 } \\
\text { antibody }\end{array}$ & $\begin{array}{c}\text { Abcam, Cambridge } \\
\text { MA, USA }\end{array}$ & Cytoplasm & $\geq$ score 3 & $240(55.8 \%)$ & Yes & OS \\
\hline $\begin{array}{l}\text { Koh } \\
2019\end{array}$ & Korea & 64 & $\mathrm{IHC}$ & $1-3$ & NSCLC & $\begin{array}{l}\text { anti-ALDH1 } \\
\text { antibody }\end{array}$ & $\begin{array}{c}\text { clone 44/ALDH, BD } \\
\text { biosciences }\end{array}$ & Cytoplasm & $\begin{array}{c}\text { H-score of } \\
93.85\end{array}$ & $267(37.5 \%)$ & Yes & OS, RFS \\
\hline
\end{tabular}

The study of Dimou 2012 et al. included two different cohorts. IHC, immunohistochemical; IF, immunofluorescence; AQUA, automated quantitative analysis; $\mathrm{H}$-score, histochemical score; NSCLC, non-small cell lung cancer; AD, adenocarcinoma; NA, not applicable; N, the number of the study population; E+, positive expression; MA, multivariate Cox analysis; HR, hazard ratio; DSS, disease-specific survival; OS, overall survival; DFS, disease-free survival; RFS, recurrence-free survival.

1-2: $\mathrm{OR}=1.16,95 \% \mathrm{CI}, 0.44-3.09, \mathrm{P}=0.763$ ) (Figure 3).

No association was found between ALDH1 expression and lymph node metastasis (four studies with 694 cases, positive $v s$. negative: $\mathrm{OR}=2.66,95 \% \mathrm{CI}, 0.63-11.25, \mathrm{P}=0.183$ ) and distal metastasis (two studies with 194 cases, positive $v s$. negative: $\mathrm{OR}=1.30,95 \% \mathrm{CI}, 0.65-2.61, \mathrm{P}=0.454$ ) (Figure 4). But ALDH1 expression was negatively correlated with vascular invasion (three studies with 562 cases, positive $v s$. negative: $\mathrm{OR}=0.63,95 \%$ CI, 0.41-0.98, $\mathrm{P}=0.04$ ) (Figure 4).

ALDH1 expression was associated with histologic subtype (six studies with 1,326 cases, AD vs. SCC:
$\mathrm{OR}=0.39,95 \% \mathrm{CI}, 0.30-0.51, \mathrm{P}<0.001)$ and recurrence (two studies with 207 cases, yes $v s$. no: $\mathrm{OR}=2.82,95 \% \mathrm{CI}$, $1.17-6.80, \mathrm{P}=0.021$ ) (Figure 5).

\section{Prognostic impact of ALDH1 expression on NSCLC and AD subtype}

The results using multivariate Cox survival analysis were summarized in Table 3. ALDH1 expression was correlated with a favorable disease-specific survival (DSS) of NSCLC (two studies with 398 cases, HR $=0.47,95 \%$ CI, 0.22-0.98, 
Table 2 Summary of the pooled results with the clinicopathological variables

\begin{tabular}{|c|c|c|c|c|c|c|}
\hline Variables & Comparison & OR with $95 \% \mathrm{Cl}$ & Heterogeneity (P) & $P$ value & Studies & Cases \\
\hline Gender & Male vs. female & $1.09(0.79-1.50)$ & 0.695 & 0.617 & 5 & 731 \\
\hline Smoking behavior & Smoking vs. nonsmoking & $1.27(0.81-1.98)$ & 0.461 & 0.292 & 3 & 385 \\
\hline Clinical stage & Stage 3-4 vs. 1-2 & $1.55(0.47-5.17)$ & $<0.001$ & 0.473 & 5 & 1,163 \\
\hline Lymph node metastasis & Positive vs. negative & $2.66(0.63-11.25)$ & $<0.001$ & 0.183 & 4 & 694 \\
\hline Distal metastasis & Positive vs. negative & $1.30(0.65-2.61)$ & 0.377 & 0.454 & 2 & 194 \\
\hline Recurrence & Yes vs. no & $2.82(1.17-6.80)$ & 0.362 & 0.021 & 2 & 207 \\
\hline Vascular invasion & Positive vs. negative & $0.63(0.41-0.98)$ & 0.806 & 0.040 & 3 & 562 \\
\hline
\end{tabular}

OR, odds ratio; $\mathrm{Cl}$, confidence interval; $\mathrm{AD}$, adenocarcinoma; SCC, squamous cell carcinoma.

Study
ID

Figure 2 Forest plot for the association between ALDH1 expression and age ( $\geq 60 v s .<60$ years), gender (male $v s$. female), and smoking behavior (smoking vs. nonsmoking). ALDH1, aldehyde dehydrogenase 1; OR, odds ratio; CI, confidence interval.

$\mathrm{P}=0.043$ ), but was not associated with $\mathrm{OS}$ (three studies with 639 cases, $\mathrm{HR}=0.89,95 \% \mathrm{CI}, 0.44-1.79, \mathrm{P}=0.736$ ) and DFS (three studies with 455 cases, HR $=1.63,95 \%$ CI, 0.59-4.54, $\mathrm{P}=0.347$ ) in NSCLC (Figure 6).

In $\mathrm{AD}$, the results showed that ALDH1 expression was not associated with $\mathrm{OS}$ (HR $=0.64,95 \% \mathrm{CI}, 0.33-1.24$, $\mathrm{P}=0.184)$ and DFS ( $\mathrm{HR}=1.47,95 \% \mathrm{CI}, 0.31-6.87, \mathrm{P}=0.628)$, but was slightly correlated with a favorable recurrence-free survival (RFS) among one study with $173 \mathrm{AD}$ patients (HR $=0.50,95 \% \mathrm{CI}, 0.27-0.95, \mathrm{P}=0.033$ ) (Figure 7).

\section{Heterogeneity analysis}

The results between ALDH1 expression and clinical stage, 


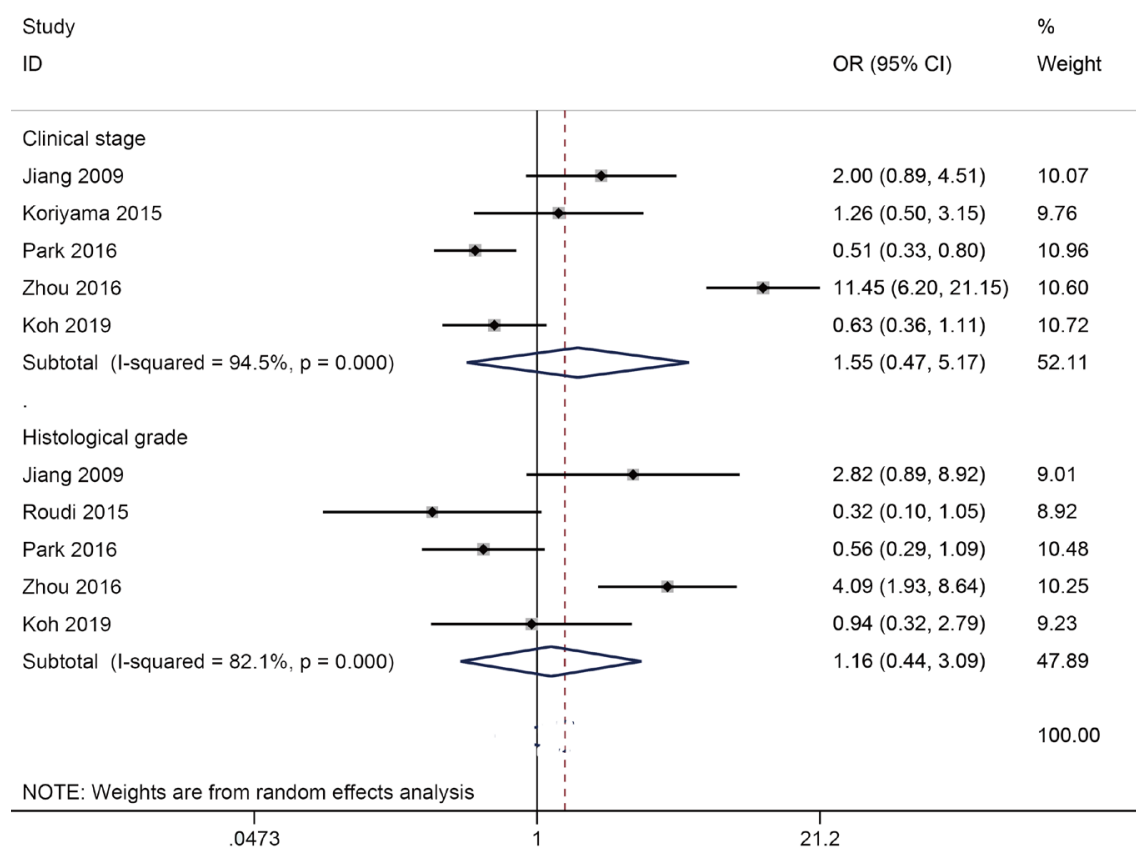

Figure 3 Forest plot for the association between ALDH1 expression and clinical stage (stage 3-4 vs. 1-2) and histological grade (grade 3 vs. 1-2). ALDH1, aldehyde dehydrogenase 1; OR, odds ratio; CI, confidence interval.

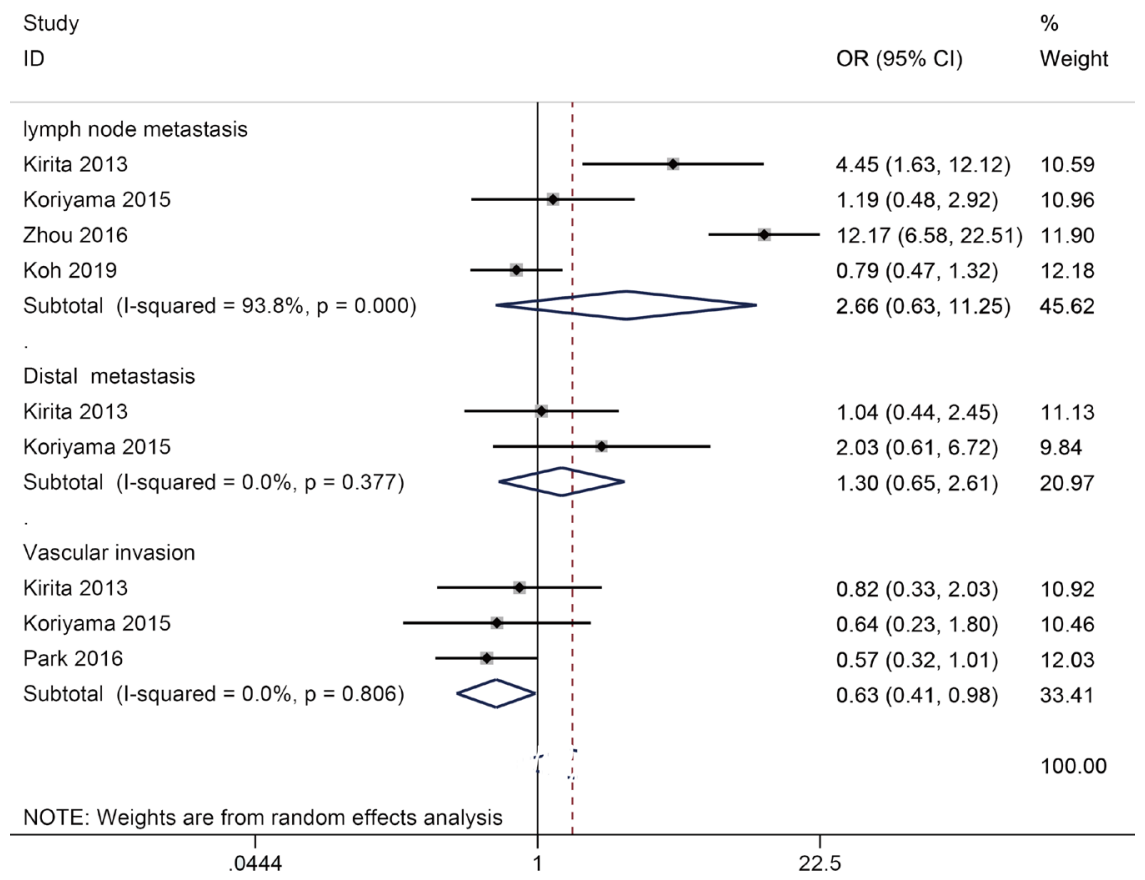

Figure 4 Forest plot for the association between ALDH1 expression and lymph node metastasis (positive vs. negative), distal metastasis (positive $v s$. negative), and vascular invasion (positive $v s$. negative). ALDH1, aldehyde dehydrogenase 1; OR, odds ratio; CI, confidence interval. 


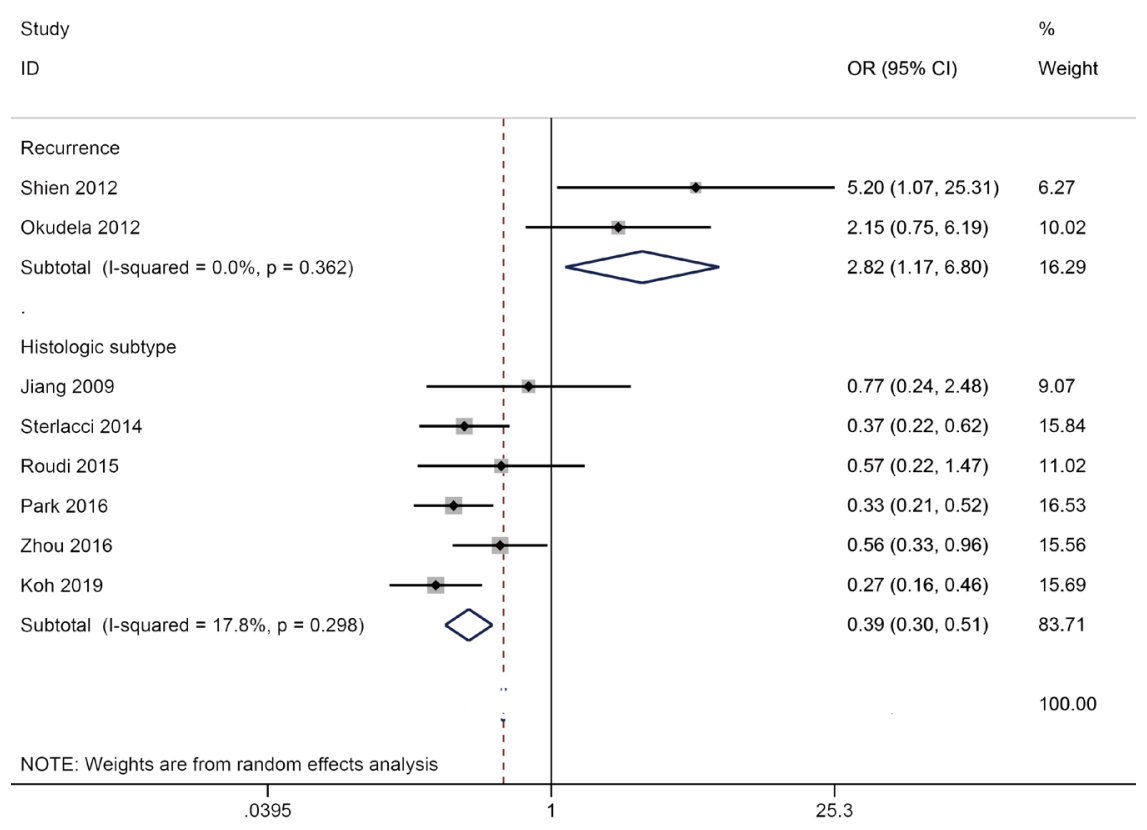

Figure 5 Forest plot for the association between ALDH1 expression and recurrence (yes vs. no) and histologic subtype (AD vs. SCC). ALDH1, aldehyde dehydrogenase 1; AD, adenocarcinoma; SCC, squamous cell carcinoma; OR, odds ratio; CI, confidence interval.

Table 3 Summary of the pooled results with the prognosis using multivariate Cox analysis

\begin{tabular}{|c|c|c|c|c|}
\hline Factors & $\mathrm{HR}$ with $95 \% \mathrm{Cl}$ & $P$ values & Studies & Cases \\
\hline \multicolumn{5}{|c|}{ In NSCLC } \\
\hline DSS & $0.47(0.22-0.98)$ & 0.043 & 2 & 398 \\
\hline OS & $0.89(0.44-1.79)$ & 0.736 & 3 & 639 \\
\hline DFS & $1.63(0.59-4.54)$ & 0.347 & 3 & 455 \\
\hline os & $0.64(0.33-1.24)$ & 0.184 & 2 & 399 \\
\hline DFS & $1.47(0.31-6.87)$ & 0.628 & 2 & 403 \\
\hline RFS & $0.50(0.27-0.95)$ & 0.033 & 1 & 173 \\
\hline
\end{tabular}

HR, hazard ratio; Cl, confidence interval; NSCLC, non-small cell lung cancer; AD, adenocarcinoma; DSS, disease-specific survival; OS, overall survival; DFS, disease-free survival; RFS, recurrence-free survival.

histological grade, and lymph node metastasis were found to have significant heterogeneity (all $\mathrm{P}<0.001$ ). We conducted sensitivity analyses to estimate the stability of the pooled results. When we removed these two studies (Kirita 2013 et al. and Zhou 2016 et al.) $(19,27)$, and re-calculated the result of the remaining studies, which was still not significant between ALDH1 expression and lymph node metastasis $(\mathrm{OR}=0.87,95 \% \mathrm{CI}, 0.56-1.36, \mathrm{P}=0.551)$, with no heterogeneity $(\mathrm{P}=0.445)$.
When two studies of Jiang 2009 et al. and Zhou 2016 et al. $(19,32)$ were removed between ALDH1 expression and clinical stage and histological grade. The re-calculated OR was 0.65 (95\% CI, 0.42-0.99, P=0.043) between ALDH1 expression and clinical stage, with no heterogeneity $(\mathrm{P}=0.222)$, and the re-calculated $\mathrm{OR}$ was 0.57 (95\% CI, 0.34-0.94, P=0.029) between ALDH1 expression and advanced histological grade, with no heterogeneity $(\mathrm{P}=0.423)$. 


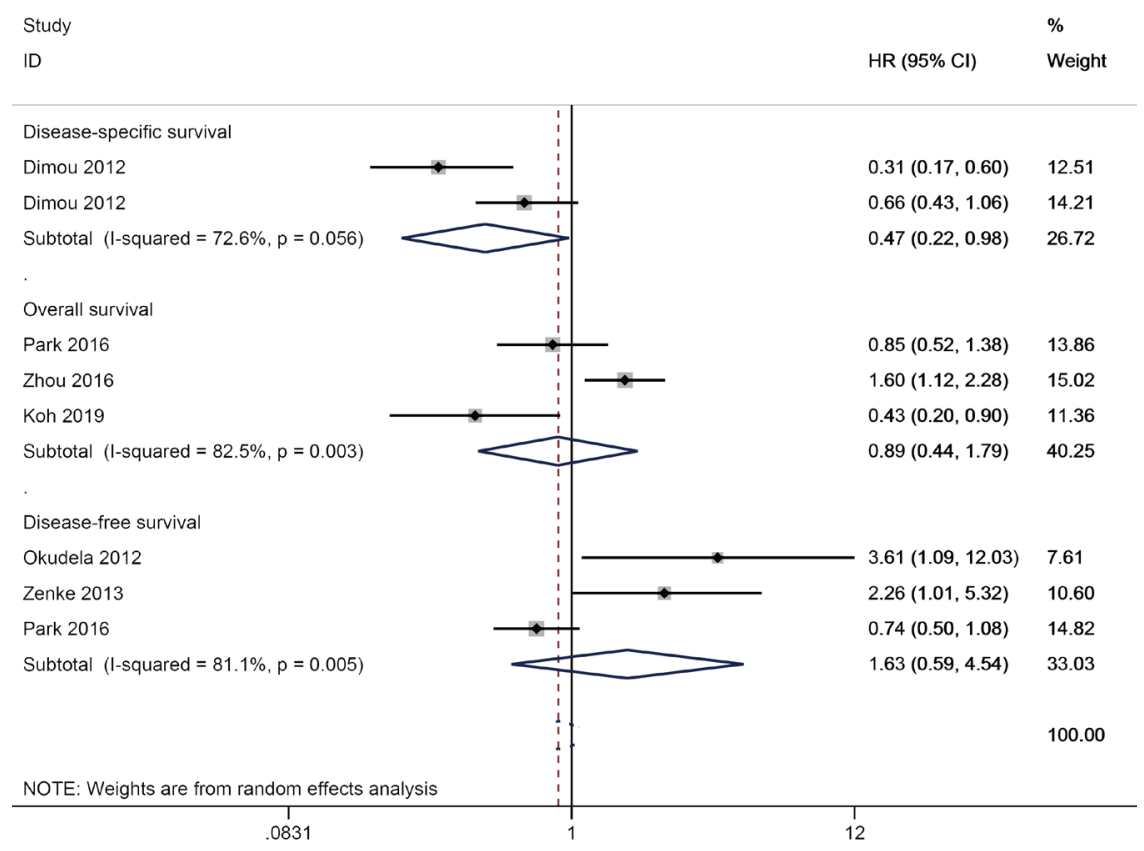

Figure 6 Forest plot for the association between ALDH1 expression the prognosis using multivariate Cox analysis in NSCLC. ALDH1, aldehyde dehydrogenase 1; NSCLC, non-small cell lung cancer; HR, hazard ratio; CI, confidence interval.

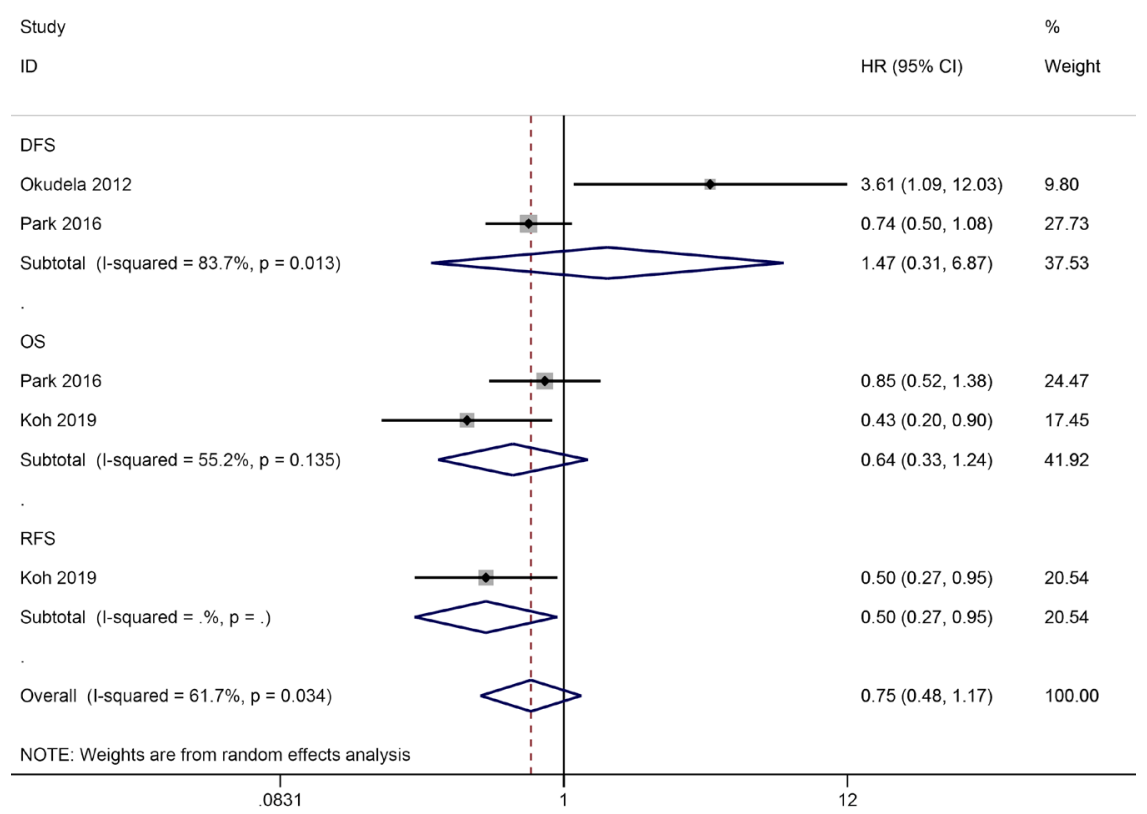

Figure 7 Forest plot for the association between ALDH1 expression the prognosis using multivariate Cox analysis in AD. ALDH1, aldehyde dehydrogenase 1; AD, adenocarcinoma; HR, hazard ratio; CI, confidence interval; OS, overall survival; DFS, disease-free survival; RFS, recurrence-free survival. 


\section{Publication bias}

No potential publication bias was detected between ALDH1 expression and gender, clinical stage, histological grade, and histologic subtype (all $\mathrm{P}$ values $>0.1$ ) (Figure S1).

\section{Discussion}

CSCs are reported to be correlated with tumor recurrence and resistance to chemotherapy and radiation $(7,8)$. Targeting CSCs may become promising and efficient targeting strategies for anticancer therapy (33). ALDH1 represents cancer stem-like properties. ALDH1 has been frequently used as a CSC marker in a variety of human cancers $(9,14)$. ALDH1 plays a crucial role in regulating retinoid metabolism, cell differentiation, proliferation, migration and invasiveness, colony formation, and EMT $(10-13,34)$. ALDH1 expression can be frequently detected in cancer and is related to the prognosis of some cancers such as ovarian, esophageal, and bladder carcinomas $(13,16,17)$. In recent years, the expression of ALDH1 is also frequently found in NSCLC $(18,25,28,30)$. However, the relationships of the expression of ALDH1 with clinicopathological characteristics and the prognostic significance in patients with NSCLC are still conflicting $(18-20,25,32)$. The current meta-analysis involving 13 eligible studies with 2,407 patients was systematically performed to estimate the clinical, pathological, and prognostic effects of ALDH1 on NSCLC.

We evaluated the relationship of ALDH1 expression with the clinicopathological characteristics of NSCLC patients. Our results demonstrated that no relationships between ALDH1 expression and age, gender, and smoking behavior were found, which were in accordance with the previous studies on age $(19,31)$, gender $(18,19,25,27,31)$, and smoking behavior $(18,27,31)$. No association is observed between ALDH1 expression and lymphovascular invasion in breast cancer (35). ALDH1 expression is positively correlated with vascular invasion in some cancers such as colorectal cancer (36) and clear cell renal cell carcinoma (37). We demonstrated a negative association between ALDH1 expression and vascular invasion in NSCLC, which was consistent with a similar result regarding a negative correlation of ALDH1 expression with lymphovascular invasion in hepatocellular carcinoma (38). These results suggest that different status of ALDH1 expression may impact the presence of vascular invasion based on different cancer types. We found that ALDH1 expression was slightly correlated with recurrence $(\mathrm{P}=0.021)$ among a small study population with 207 cases. But Okudela 2012 et al. reported that the difference was not statistically significant between ALDH1 expression and recurrence in $177 \mathrm{AD}$ cases (29). Koh 2019 et al. reported that ALDH1 expression was slightly associated with a favorable RFS $(\mathrm{P}=0.033)$ in $173 \mathrm{AD}$ cases (18). Therefore, the current results on recurrence or RFS should be interpreted with caution, as only one study or two studies with small sample sizes were included. More studies with larger sample sizes are very necessary to further validate the association of ALDH1 expression with recurrence or RFS. ALDH1 expression was significantly lower in AD than in SCC (AD vs. SCC: $\mathrm{OR}=0.39, \mathrm{P}<0.001$, which was in accordance with the previous publications $(18-20,28)$. ALDH1 expression was not associated with OS and DFS in AD. Additionally, data from the KM plotter database (http://kmplot.com/analysis/ index.php? p=background) (39) showed that ALDH1 low expression was associated with poor progression-free survival (PFS) in $\mathrm{AD}(\mathrm{HR}=1.69, \mathrm{P}=0.0011)$, but was not correlated with PFS in SCC $(\mathrm{P}=0.77)$ (Figure S2). These results suggested that ALDH1 may play a more key role in the pathogenesis of $\mathrm{AD}$.

ALDH1 expression was not correlated with clinical stage, histological grade, lymph node metastasis, and distal metastasis. Additionally, substantial heterogeneity was observed between ALDH1 and clinical stage, histological grade, and lymph node metastasis $(\mathrm{P}<0.001)$. Thus, sensitivity analyses were conducted to evaluate the stability of the pooled results. Sensitivity analysis revealed that the association of ALDH1 with lymph node metastasis was still not significant. When we removed these two studies of Jiang 2009 et al. and Zhou 2016 et al. $(19,32)$ and the recalculated results showed no heterogeneity $(\mathrm{P}>0.1)$, but we found that ALDH1 expression was negatively correlated with advanced clinical stage $(\mathrm{OR}=0.65, \mathrm{P}=0.043)$ and histological grade $(\mathrm{OR}=0.57, \mathrm{P}=0.029)$ based on sensitivity analyses. Although the expression of ALDH1 was selected using an anti-ALDH1 antibody to reduce the selection bias, the potential reasons for heterogeneity were still not clear. Possibly due to the use of unavoidable sources of antiALDH1 antibody and different cut-off values of ALDH1 staining from the included studies, which might cause the potential sources of the observed heterogeneity.

We finally evaluated whether ALDH1 expression was related to the prognosis of NSCLC using multivariate Cox survival analysis. Data demonstrated that ALDH1 expression was not correlated with OS and DFS, but was 
associated with improved DSS, which suggested that ALDH1 may be an independent favorable prognostic biomarker for DSS. We found ALDH1 expression may be negatively associated with advanced clinical stage, histological grade from sensitivity analyses, and vascular invasion, suggesting that ALDH1 expression may be correlated with favorable prognostic clinicopathological characteristics, which may further impact the prognosis and were consistent with favorable DSS. More studies are strongly needed to further confirm our findings in the future.

The present meta-analysis presented certain limitations. First, the Caucasian and Asian populations were mainly included, other ethnic groups, such as Africans are lacking. Second, the cut-off values and sources of the anti-ALDH1 antibody varied across many studies, which should be done based on a uniform standard in the future. Third, sensitivity analyses showed that the results of ALDH1 expression with clinical stage and histological grade were not stable; additional studies with large sample sizes are essential to further determine the results. Fourth, sample sizes were relatively small between ALDH1 expression and some clinicopathological variables such as age, smoking behavior, distal metastasis, vascular invasion, recurrence. Finally, based on the use of multivariate Cox analysis, more studies are necessary to further validate the prognostic significance of ALDH1 expression on NSCLC patients in the future.

In conclusion, the present meta-analysis demonstrated no association between ALDH1 expression and age, gender, smoking behavior, clinical stage, histological grade, lymph node metastasis, and distal metastasis, but showed a negative correlation of ALDH1 expression with vascular invasion. ALDH1 expression presented a lower frequency in AD. ALDH1 expression was not related to OS and DFS, but was correlated with favorable DSS in NSCLC patients. In the future, more studies with larger sample sizes are needed to obtain definitive conclusions regarding the prognostic effect of ALDH1 in NSCLC.

\section{Acknowledgments}

Funding: None.

\section{Footnote}

Conflicts of Interest: All authors have completed the ICMJE uniform disclosure form (available at http://dx.doi. org/10.21037/tcr.2020.02.09). The authors have no conflicts of interest to declare.
Ethical Statement: The authors are accountable for all aspects of the work in ensuring that questions related to the accuracy or integrity of any part of the work are appropriately investigated and resolved.

Open Access Statement: This is an Open Access article distributed in accordance with the Creative Commons Attribution-NonCommercial-NoDerivs 4.0 International License (CC BY-NC-ND 4.0), which permits the noncommercial replication and distribution of the article with the strict proviso that no changes or edits are made and the original work is properly cited (including links to both the formal publication through the relevant DOI and the license). See: https://creativecommons.org/licenses/by-nc-nd/4.0/.

\section{References}

1. Bray F, Ferlay J, Soerjomataram I, et al. Global cancer statistics 2018: GLOBOCAN estimates of incidence and mortality worldwide for 36 cancers in 185 countries. CA Cancer J Clin 2018;68:394-424.

2. Socinski MA, Obasaju C, Gandara D, et al. Clinicopathologic Features of Advanced Squamous NSCLC. J Thorac Oncol 2016;11:1411-22.

3. Chatterjee S, Bhattacharya S, Socinski MA, et al. HSP90 inhibitors in lung cancer: promise still unfulfilled. Clin Adv Hematol Oncol 2016;14:346-56.

4. Blandin Knight S, Crosbie PA, Balata H, et al. Progress and prospects of early detection in lung cancer. Open Biol 2017. doi: 10.1098/rsob.170070.

5. Han S, Huang T, Li W, et al. Prognostic Value of CD44 and Its Isoforms in Advanced Cancer: A Systematic MetaAnalysis With Trial Sequential Analysis. Front Oncol 2019;9:39.

6. Han S, Huang T, Wu X, et al. Prognostic Value of CD133 and SOX2 in Advanced Cancer. J Oncol 2019;2019:3905817.

7. Loureiro R, Mesquita KA, Magalhaes-Novais S, et al. Mitochondrial biology in cancer stem cells. Semin Cancer Biol 2017;47:18-28.

8. Huang R, Rofstad EK. Cancer stem cells (CSCs), cervical CSCs and targeted therapies. Oncotarget 2017;8:35351-67.

9. Tomita H, Tanaka K, Tanaka T, et al. Aldehyde dehydrogenase $1 \mathrm{~A} 1$ in stem cells and cancer. Oncotarget 2016;7:11018-32.

10. Tahara S, Nojima S, Ohshima K, et al. Serum deprivationresponse protein regulates aldehyde dehydrogenase 1 through integrin-linked kinase signaling in endometrioid 
carcinoma cells. Cancer Sci 2019;110:1804-13.

11. Chang MT, Lee SP, Fang CY, et al. Chemosensitizing effect of honokiol in oral carcinoma stem cells via regulation of IL-6/Stat3 signaling. Environ Toxicol 2018;33:1105-12.

12. Wang TY, Yu CC, Hsieh PL, et al. GMI ablates cancer stemness and cisplatin resistance in oral carcinomas stem cells through IL-6/Stat3 signaling inhibition. Oncotarget 2017;8:70422-30.

13. Chen MF, Chen PT, Lu MS, et al. Role of ALDH1 in the prognosis of esophageal cancer and its relationship with tumor microenvironment. Mol Carcinog 2018;57:78-88.

14. Han S, Huang T, Wu X, et al. Prognostic value of ALDH1 and Nestin in advanced cancer: a systematic meta-analysis with trial sequential analysis. Ther Adv Med Oncol 2019;11:1758835919830831.

15. Oria VO, Bronsert P, Thomsen AR, et al. Proteome Profiling of Primary Pancreatic Ductal Adenocarcinomas Undergoing Additive Chemoradiation Link ALDH1A1 to Early Local Recurrence and Chemoradiation Resistance. Transl Oncol 2018;11:1307-22.

16. Ruscito I, Darb-Esfahani S, Kulbe H, et al. The prognostic impact of cancer stem-like cell biomarker aldehyde dehydrogenase-1 (ALDH1) in ovarian cancer: A metaanalysis. Gynecol Oncol 2018;150:151-7.

17. Xu N, Shao MM, Zhang HT, et al. Aldehyde dehydrogenase 1 (ALDH1) expression is associated with a poor prognosis of bladder cancer. Cancer Epidemiol 2015;39:375-81.

18. Koh YW, Han JH, Haam S, et al. ALDH1 expression correlates with an epithelial-like phenotype and favorable prognosis in lung adenocarcinoma: a study based on immunohistochemistry and mRNA expression data. J Cancer Res Clin Oncol 2019;145:1427-36.

19. Zhou L, Yu L, Zhu B, et al. Metastasis-associated in colon cancer-1 and aldehyde dehydrogenase 1 are metastatic and prognostic biomarker for non-small cell lung cancer. BMC Cancer 2016;16:876.

20. Park E, Park SY, Sun PL, et al. Prognostic significance of stem cell-related marker expression and its correlation with histologic subtypes in lung adenocarcinoma. Oncotarget 2016;7:42502-12.

21. Shamseer L, Moher D, Clarke M, et al. Preferred reporting items for systematic review and meta-analysis protocols (PRISMA-P) 2015: elaboration and explanation. BMJ 2015;350:g7647.

22. Hoaglin DC. Misunderstandings about Q and 'Cochran's $Q$ test' in meta-analysis. Stat Med 2016;35:485-95.
23. Bowden J, Davey Smith G, Burgess S. Mendelian randomization with invalid instruments: effect estimation and bias detection through Egger regression. Int J Epidemiol 2015;44:512-25.

24. Roudi R, Korourian A, Shariftabrizi A, et al. Differential Expression of Cancer Stem Cell Markers ALDH1 and CD133 in Various Lung Cancer Subtypes. Cancer Invest 2015;33:294-302.

25. Koriyama H, Ishii G, Yoh K, et al. Presence of podoplanin-positive cancer-associated fibroblasts in surgically resected primary lung adenocarcinoma predicts a shorter progression-free survival period in patients with recurrences who received platinum-based chemotherapy. J Cancer Res Clin Oncol 2015;141:1163-70.

26. Zenke $\mathrm{Y}$, Ishii G, Ohe $\mathrm{Y}$, et al. Aldehyde dehydrogenase 1 expression in cancer cells could have prognostic value for patients with non-small cell lung cancer who are treated with neoadjuvant therapy: identification of prognostic microenvironmental factors after chemoradiation. Pathol Int 2013;63:599-606.

27. Kirita K, Ishii G, Matsuwaki R, et al. Identification of biological properties of intralymphatic tumor related to the development of lymph node metastasis in lung adenocarcinoma. PLoS One 2013;8:e83537.

28. Sterlacci W, Savic S, Fiegl M, et al. Putative stem cell markers in non-small-cell lung cancer: a clinicopathologic characterization. J Thorac Oncol 2014;9:41-9.

29. Okudela K, Woo T, Mitsui H, et al. Expression of the potential cancer stem cell markers, CD133, CD44, ALDH1, and beta-catenin, in primary lung adenocarcinoma--their prognostic significance. Pathol Int 2012;62:792-801.

30. Dimou A, Neumeister V, Agarwal S, et al. Measurement of aldehyde dehydrogenase 1 expression defines a group with better prognosis in patients with non-small cell lung cancer. Am J Pathol 2012;181:1436-42.

31. Shien K, Toyooka S, Ichimura K, et al. Prognostic impact of cancer stem cell-related markers in non-small cell lung cancer patients treated with induction chemoradiotherapy. Lung Cancer 2012;77:162-7.

32. Jiang F, Qiu Q, Khanna A, et al. Aldehyde dehydrogenase 1 is a tumor stem cell-associated marker in lung cancer. Mol Cancer Res 2009;7:330-8.

33. Eun K, Ham SW, Kim H. Cancer stem cell heterogeneity: origin and new perspectives on CSC targeting. BMB Rep 2017;50:117-25.

34. Martinez-Cruzado L, Tornin J, Santos L, et al. Aldh1 Expression and Activity Increase During Tumor Evolution 
in Sarcoma Cancer Stem Cell Populations. Sci Rep 2016;6:27878.

35. Liu JF, Xia P, Hu WQ, et al. Aldehyde dehydrogenase 1 expression correlates with clinicopathologic features of patients with breast cancer: a meta-analysis. Int J Clin Exp Med 2015;8:8425-32.

36. Holah NS, Aiad HA, Asaad NY, et al. Evaluation of the Role of ALDH1 as Cancer Stem Cell Marker in Colorectal Carcinoma: An Immunohistochemical Study. J Clin Diagn Res 2017;11:EC17-EC23.

37. Wang K, Chen X, Zhan Y, et al. Increased expression of

Cite this article as: Xue J, Zhao Y, Zou Q, Liang F, Lin F. The clinical and prognostic impact of aldehyde dehydrogenase 1 in non-small cell lung cancer: a meta-analysis. Transl Cancer Res 2020;9(3):1914-1925. doi: 10.21037/tcr.2020.02.09
ALDH1A1 protein is associated with poor prognosis in clear cell renal cell carcinoma. Med Oncol 2013;30:574.

38. Tanaka K, Tomita H, Hisamatsu K, et al. ALDH1A1overexpressing cells are differentiated cells but not cancer stem or progenitor cells in human hepatocellular carcinoma. Oncotarget 2015;6:24722-32.

39. Nagy A, Lanczky A, Menyhart O, et al. Validation of miRNA prognostic power in hepatocellular carcinoma using expression data of independent datasets. Sci Rep 2018;8:9227. 


\section{Supplementary}

Table S1 Detailed characterisitics of the included studies with the clinicopathological variables

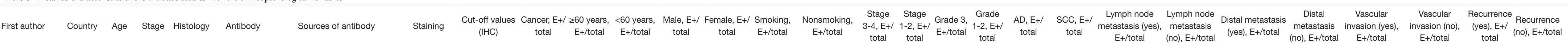

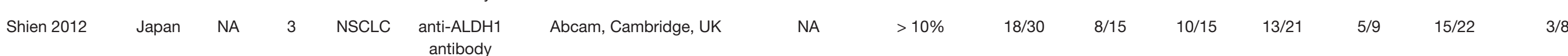

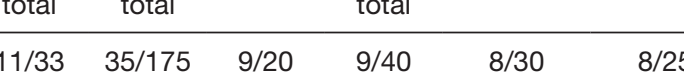
$\begin{array}{llllllllll}\text { Okudela 2012 Japan } & 68 & 1 & \text { AD } & \begin{array}{c}\text { anti-ALDH1 } \\ \text { antibody }\end{array} & \text { Abcam, Cambridge, UK } & \begin{array}{c}\text { Cytoplasm/ } \\ \text { membrane }\end{array} & 285 \% & 36 / 177\end{array}$

$\begin{array}{lllllllll}\text { Kirita } 2013 & \text { Japan } & 67 & \text { NA } & \text { AD } & \begin{array}{c}\text { anti-ALDH1 } \\ \text { antibody }\end{array} & \begin{array}{c}\text { clone 4AALH; BD Bioscience, Cytoplasm/ } \\ \text { San Jose, CA, USA } \\ \text { nuclei }\end{array} & \text { Median } & 36 / 107\end{array}$ Sterlacci 2014 Austria NA $\quad 1-4$ NSCLC $\begin{aligned} & \text { anti-ALDH1 } \\ & \text { antibody }\end{aligned}$ Clone ab51028, Abcam Cytoplasm Median $107 / 336$

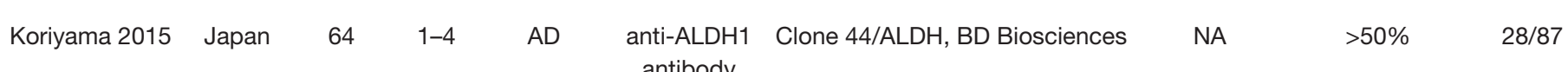

(t)

IHC, immunohistochemical; H-score, histochemical score; NSCLC, non-small cell lung cancer; AD, adenocarcinoma; SCC, squamous cell carcinoma; NA, not applicable; E+, positive expression. 

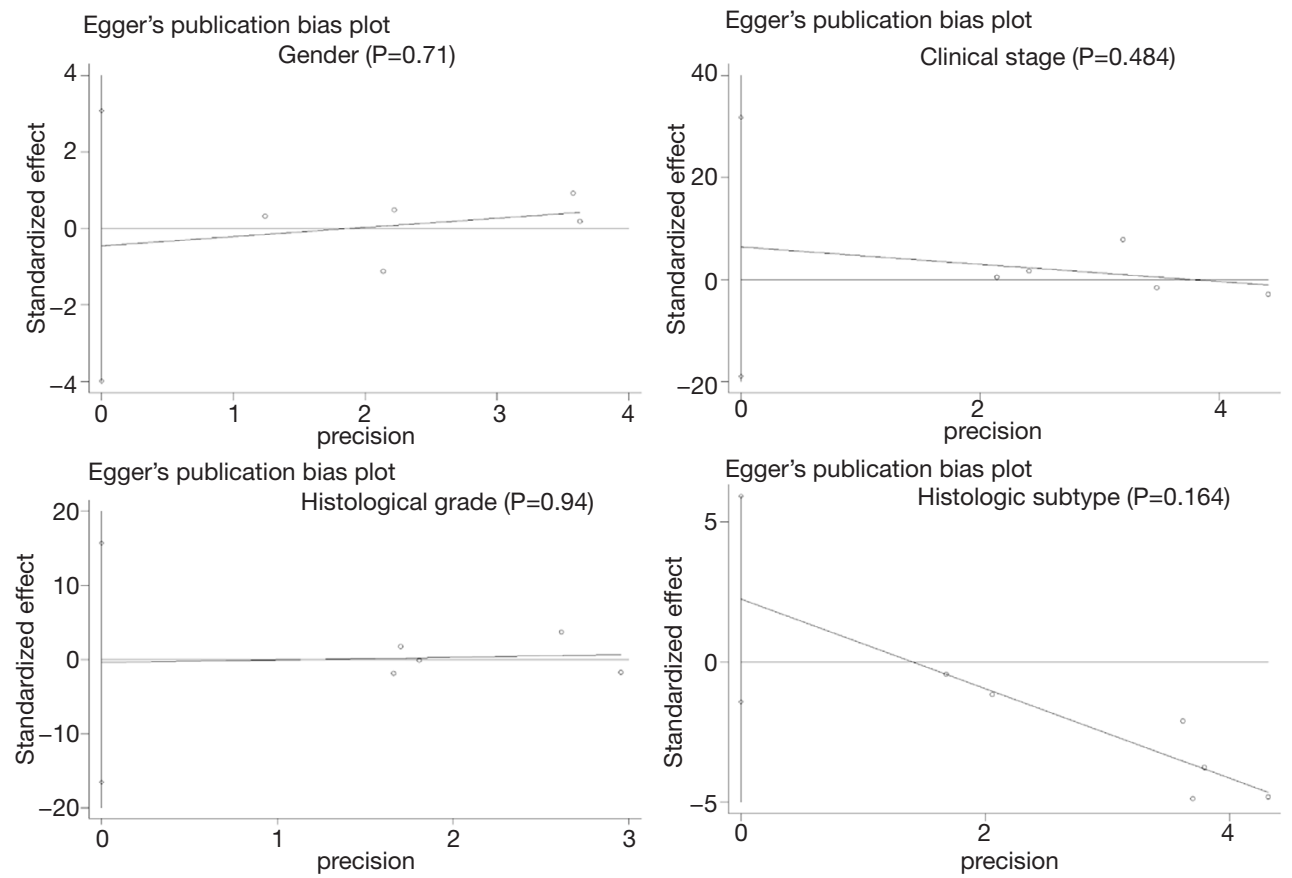

Figure S1 Publication bias using Egger's test.
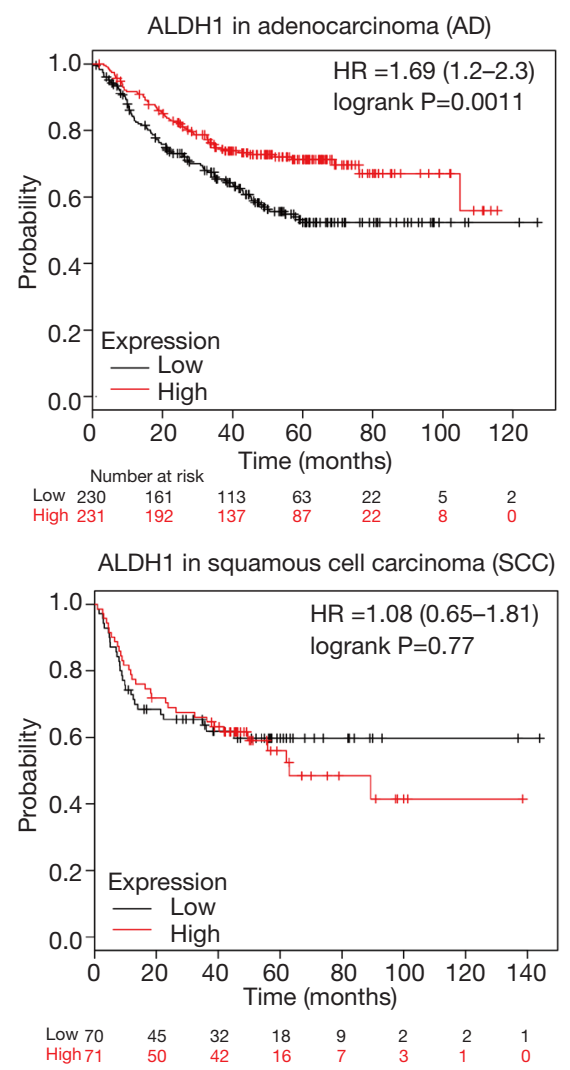

Figure S2 KM plotter of ALDH1 expression with progression-free survival (PFS) in adenocarcinoma (AD) and squamous cell carcinoma (SCC). 